\title{
OS VAZIOS DA ASSISTÊNCIA OBSTÉTRICA: REFLEXÕES SOBRE O PARTO A PARTIR DE UM ESTUDO ETNOGRÁFICO*
}

Dulce Maria Rosa Gualda**

GUALDA, D.R.M. Os vazios da assistência obstétrica: reflexōes sobre o parto a partir de um estudo etnográfico. Rev.Esc.Enf.USP, v.28, n.3, p. 332-6, dez. 1994.

A proposta deste trabalho foi explorar algumas falhas na assistência à mulher durante o parto no contexto atual. Após breve relato da evoluçāo histórica da assistên. cia ao parto e dos resultados de uma pesquisa etnográfica sobre a vivência do parto, sāo feitas algumas consideraçōes sobre a situação atual do atendimento ao parto. Esta caracteriza-se pela falta de autonomia na tomada de decisóes e pela falta de controle do processo de nascimento por parte das mulheres, que é apontada como sendo resultado do distanciamento entre o conhecimento profissional e o conhecimento popular.

UNITERMOS: Parto. Cuidado cultural. Assistência obstétrica.

Ao longo das últimas décadas temos presenciado grandes progressos científicos que têm causado um forte impacto na área obstétrica, tanto em termos de necessidades assistenciais de nossa clientela quanto de capacidade profissional de atender a elas, no âmbito das instituições prestadoras de serviços de saúde.

No que se refere a assistência ao parto, tem havido uma preocupação acentuada por parte dos profissionais de se apoiar num sistema científico afim de garantir a qualidade de cuidado, de modo a oferecer maior segurança para a mãe e para o bebê.

Em contrapartida, tem havido um descaso por parte dos profissionais de considerar os aspectos psico-sócio-culturais do processo reprodutivo. Isto tem suscitado uma série de questões polêmicas que envolvem qualidade da assistência ao parto e o significado da experiência do nascimento no mundo civilizado.

- Trabalho apresentado na mesa redonda realizada em comemoraçáo ao dia da Obstetriz e Enfermeira Obstetra. 12/04/94, promovida pela Associaçăo Brasileira de Obstetrizes e Enfermeiros Obstetras (ABENFO.SP).

* Professor Doutor do Departamento de Enfermagem Materno Infantil e Psiquiátrica da Escola de Enfermagem da USP. Diretora da Divisåo Materno Infantil do Hospital Universitário da Universidade de Såo Paulo. 
Uma das questões essenciais, que precisa ser contemplada, é a da autonomia nas decisões e a capacidade da mulher de controlar o processo do nascimento.

A evolução do atendimento ao parto permite-nos fazer uma análise reflexiva da situação atual.

Em seus primórdios, o nascimento era considerado um espaço feminino por excelência. Era um ir e vir de mulheres à cabeceira da parturiente. Quem prestava assistência eram mulheres que tinham vivenciado partos bem sucedidos, ou que tinham, empiricamente adquirido experiência dessa prática, considerada então essencialmente feminina. Neste contexto, o parto era considerado um evento social, com significado comum àquelas pessoas envolvidas na situação social, do qual a parturiente participava ativamente.

Numa fase seguinte, a partir do século XVIII, este panorama assistencial começa a sofrer alteraçōes, pois a medicina, enquanto instituição, incorpora esta prática, denominando-a de Arte Obstétrica. Com a entrada em cena dos médicos, com seus instrumentos e intervenções, ainda em território doméstico, começa a substituição da parteira leiga. Há, concomitantemente, uma mudança de mentalidade a respeito do ato de dar a luz, que progressivamente desloca a atenção da mãe para o bebê, deixando gradualmente a mulher relegada ao papel de objeto no processo de parturição.

Numa última etapa, institui-se a prática do parto hospitalar que imprime as características do atendimento obstétrico do século XX. A transferência do parto para o contexto hospitalar, que foi simultânea ao desenvolvimento tecnológico e à profissionalização da medicina, atribuiu aos especialistas a responsabilidade da assistência obstétrica. (ARRUDA, 1989).

Houve ganhos e perdas. A institucionalização do parto trouxe maior segurança, proporcionou um declínio na morbi-mortalidade perinatal e melhores condições de controle da dor através da anestesia.

No entanto, se analisarmos numa perspectiva ampla, o parto tornou-se um momento de alienação do corpo, do ambiente doméstico, dos familiares e amigos, da vida em si. Como afirma MICHAELSON (1988), os procedimentos seguros tornaram-se uma espécie de produção industrial. A mulher tornou-se impotente diante da experiência vivida, incapaz de buscar o seu significado, uma vez que a sua consciência do processo e a sua participação no evento foram reduzidas ao mínimo. Esta situação, que se caracteriza pela falta de autonomia nas decisões e falta de controle do processo do nascimento, deve-se fundamentalmente ao distanciamento entre o conhecimento profissional e o conhecimento popular.

O conhecimento profissional é o de domínio de pessoas que foram formalmente preparadas para o desempenho de cuidado e cura, que possuem valores culturais próprios e específicos e que têm uma formação fundamentada na anatomia e na fisiologia articulada ao desenvolvimento técnico-científico que se operacionaliza através do modelo assistencial médico vigente.

Por outro lado, o conhecimento popular, de domínio da clientela, é construído a partir de um sistema de crenças e de valores culturais que as pessoas de um determinado grupo fazem uso para tomar as decisões, para 
orientar as ações, para interpretar a experiência vivida e para adotar um comportamento social de acordo com os significados atribuidos a cada situação. O conhecimento popular é construído no cotidiano, a partir da vivência individual e coletiva e da transmissão de informações dos elementos da mesma cultura.

Assim sendo, por suas próprias características, muitas vezes o saber profissional entre em choque com o saber popular.

Especificamente no parto, esta afirmação está fundamentada no estudo concluído no ano de 1993 que foi minha tese de doutorado, cujo título é "Eu conheço minha natureza"; um estudo etnográfico da vivência do parto (GUALDA, 1993). Ela retrata o conhecimento das mulheres a respeito do parto. Constatei que, na sua perspectiva, a natureza constituía o eixo central de todo o processo, e conhecer a natureza era uma prerrogativa de cada mulher. Assim, no tema central foram identificados dois elementos básicos: a natureza e a experiência. A natureza foi interpretada sob dois aspectos: características das pessoas e caracteristicas do processo de parto. As características das pessoas englobam tanto atributos universais próprios do ser humano, quanto atributos singulares de cada um. No que se refere à natureza do processo de parto, estão incluídos tanto a universalidade do processo de parto quanto peculiaridades de cada experiência.

Neste sentido, o parto é considerado um acontecimento natural na vida da mulher, e cada um deles tem caracteristicas próprias e únicas para cada uma delas.

Cabe, portanto, a cada mulher conhecer a sua natureza e isto procede da experiência. Acreditam que, só através da vivência, é possível conhecer a si própria e o seu processo de parto. Isto se opera de modo gradativo na sucessão dos partos e confere à mulher autonomia para tomar decisões e agir em benefício próprio durante este período.

Outro aspecto importante que ficou evidenciado diz respeito à dor do parto. Ela também está permeada pela natureza. Dor de parto foi considerada um componente natural e essencial da maternidade. Embora ela represente sofrimento, as mulheres expressam o desejo de experimentá-la e sentem-se capazes de tolerá-la.

Finalmente, o último aspecto emergido da análise diz respeito à participação do bebê no processo do parto em todas as suas fases, principalmente no que se refere ao determinismo do parto. Nesta abordagem, a natureza, através das condições do bebê é que determina o momento exato do nascimento e sua participação no mecanismo do parto.

Ao rever livros especializados para averiguar as explicações científicas sobre os tópicos abordados nos temas sintetizados, a partir do conhecimento das mulheres, encontrei várias lacunas no conhecimento científico que pudessem servir de suporte para as condutas e intervençōes obstétricas. Isto me fez julgar que a natureza ainda permeia todo o processo do parto na perspectiva científica, apesar de todo desenvolvimento tecnológico, embora seja difícil para o profissional assumir tal fato. Nestas circunstâncias, cabe ao profissio- 
nal tomar decisões com base na sua formação, na sua experiência e no seu critério de valores que lhe foi culturalmente transmitido.

A conduta obstétrica, muitas vezes, contrapos-se aos valores culturais do saber popular que assume, de fato, a natureza como centro do processo, cujo conhecimento advém da experiência e da formação recebida de sua rede de apoio. A divergência de concepção gerou situações de conflito entre profíssionais e clientela na qual se evidenciou um descaso do conhecimento da mulher a respeito do seu próprio corpo e prevaleceu, na maioria das vezes, 0 poder médico em detrimento da qualidade da experiência vivida e da assistência recebida pelas mulheres.

$O$ que pude constatar também, a partir das reflexões sobre os temas encontrados, é que esta falta de conhecimento não é unilateral, mas sim recíproca. Além da dificuldade das mulheres e das pessoas envolvidas de conhecer as peculiaridades de cada experiência do parto, a maioria não tem acesso ao conhecimento especializado de domínio do profissional. Esta situação, conseqüentemente, favorece a falta de controle do parto e a falta de autonomia nas decisões, pois estas pessoas delegam a condução do parto ao profissional, que possui informação médica ou técnica.

Como agravante, em termos quantitativos, numa visão mais ampla do problema, temos que considerar que o privilégio do atendimento médico se restringe a camadas minoritárias da população, àquelas mulheres cuja condição financeira consegue enfrentar o custo operacional da assistência obstétrica médico-hospitalar. A maioria da população, justamente as que mais necessitam de atendimento, não tem condições de encarar o crescente aumento do custo da assistência médica ao parto. As que fazem uso do Sistema Único de Saúde, em decorrência da sua situação econômica, experimentam a dificuldade de chegar ao hospital, de não encontrar vagas, de ter que ser transferidas para hospitais distantes para obter assistência, de ter que procurar vários hospitais em busca de atendimento. Isto, por si só, é uma negação de opção, uma negação do direito à cidadania.

Diante deste quadro, não pretendo fazer a apologia do parto domiciliar ou mesmo parto alternativo. Considero que o ponto negativo não é nem o hospital, nem são os avanf̧os técnicos em si, mas o controle perverso que eles favorecem. Como afirma ARRUDA (1989), a intervenção do profissional pode trazer, e traz, benefícios, mas ela seria vista mais positivamente se não se expressassem sob suas normas, atitudes que retratam uma visão estereotipada da mulher como ser inferior, que é tratada como ignorante, incapaz de emitir opinião sobre o que está sucedendo, e que deve curvar-se sem questionar o saber inatacável daqueles que trarão ao mundo seu bebê são e salvo.

Temos que, enquanto profissionais da enfermagem obstétrica, repensar a nossa prática, buscarmos uma simplicidade sem dispensar a eficiência. Temos que protestar contra o uso indevido e sistematizado de tecnologia que onera, desnecessariamente, os custos do atendimento à mulher durante o parto. Temos que mudar a nossa atitude tendo como meta melhorar a assistência à mulher durante o período do parto. A mudança de atitude implica numa vontade consciente de recodificar o saber cientificamente 
aprendido, reconhecer o sistema cultural contextualizado e trabalhar com os nossos clientes nas soluções possiveis para as dificuldades encontradas no momento do parto.

GUALDA, D.R.M. The gaps in maternity care: reflexion about care delivery in childbirth based on an ethnographic research. Rev.Esc.Enf.USP, v.28, n.3, p.332-6, dec. 1994.

The aim of this paper was to explore some gaps in maternity care of women during labor and delivery. Based on the findings of an ethnographic research about the women's experiences in childbirth process the autor analyses care delivered to women in this phase. The gaps in the present situation that is characterezed by lack of authonomy in decision making and lack of ability to control birth process, are attributed to the shock beteveen professional and popular knowledge.

UNITERMS: Childbirth. Cultural care. Maternity care.

\section{REFERÊNCIAS BIBLIOGRÁFICAS}

ARRUDA, A. Um atendimento ao parto para fazer ver e nascer. In: ENCONTRO NACIONAL DE SAÚDE DA MULHER - UM DIREITO A SER CONQUISTADO, Brasilia, 1989. Relatório, Brasilia, Conselho Nacional dos Direitos da mulher - CNDM, Ministério da Justiça, 1989 , p. 35-41.

GUALDA, D.M.R. "Eu conheço minha natureza": um estudo etnografico da vivência do parto. São Paulo, 1993. 288p. Tese (Doutorado) Escola de Enfermagem, Universidade de Sào Paulo.

MICHAELSON, K.L. Childbirth in America: a brief history and contemporary issues. In: MICHAELSON, K.L. et al. Childbirth in America: antropological perspectives. South Hodley, Bergin \& Garvery Publishers, 1988, p.1-32 